\title{
The role of the ipsilesional side in the rehabilitation of post- stroke subjects
}

\author{
Augusta Silva (PhD) \\ Escola Superior de Saúde do Porto, Centro de Estudos de Movimento e Actividade Humana, \\ Instituto Politécnico do Porto, Physiotherapy \\ Rua Dr. António Bernardino de Almeida, 4004200 - 072, Porto \\ Porto, PT 4250-505 \\ E-mail: smaugusta@gmail.com \\ (Corresponding author) \\ Andreia S. P. Sousa (PhD) \\ Escola Superior de Saúde do Porto, Centro de Estudos de Movimento e Actividade Humana, \\ Instituto Politécnico do Porto, Physiotherapy \\ Rua Dr. António Bernardino de Almeida, 4004200 - 072, Porto \\ Porto, PT 4250-505 \\ E-mail: asp@ess.ipp.pt,andreia.asps@gmail.com
}

Cláudia Silva, PhD

Escola Superior de Saúde do Porto, Centro de Estudos de Movimento e Actividade Humana, Instituto Politécnico do Porto, Physiotherapy

Rua Dr. António Bernardino de Almeida, 4004200 - 072, Porto

Porto, PT 4250-505

E-mail: claudiacostasilva78@gmail.com

Rubim Santos $(\mathrm{PhD})$

Escola Superior de Saúde do Porto, Centro de Estudos de Movimento e Actividade Humana, Instituto Politécnico do Porto, Physics

Rua Dr. António Bernardino de Almeida, 4004200 - 072, Porto

Porto, PT 4250-505

E-mail: $\underline{\text { rss@ess.ipp.pt }}$

João Manuel R. S. Tavares (PhD)

Instituto de Ciência e Inovação em Engenharia Mecânica e Engenharia Industrial, Departamento de Engenharia Mecânica, Faculdade de Engenharia, Universidade do Porto, Rua Dr. Roberto Frias, s/n, 4200-465 Porto, PORTUGAL

E-mail: tavares@fe.up.pt

Filipa Sousa $(\mathrm{PhD})$ 
Laboratório de Biomecânica do Porto, Faculdade de Desporto da Universidade do Porto, Porto, PORTUGAL

E-mail: filipas@fade.up.pt 


\begin{abstract}
Most stroke lesions occur in the middle cerebral artery territory, presenting a high probability of damage of pathways with predominant ipsilesional disposition, mainly related to postural control. Despite the high probability of bilateral postural control dysfunction based on neuroanatomical fundaments, both research and clinical rehabilitation involving stroke subjects have been focused on contralesional side (also named affected side) impairments, while ipsilesional side (also named non-affected side) impairments have been attributed to an adaptive strategy.

This paper aims to present a critical understanding about the state-of-the-art that sustains the hypothesis that stroke subjects with middle cerebral artery territory lesion at the subcortical level show an atypical behaviour in the ipsilateral side associated with the lesion itself and the possible implications.
\end{abstract}

Keywords: Stroke; Ipsilesional side; Postural control; Rehabilitation. 


\section{1- Introduction}

Epidemiological data show that most stroke subjects have a lesion in the middle cerebral artery territory (Mohr et al., 2004) at a subcortical level (Crafton et al., 2003; Schiemanck et al., 2006), which is why there is a high probability of an injury affecting the corticoreticular connection. Through this connection, the cerebral cortex, mostly the Brodmann's area 6 including the pre-motor cortex and the supplementary area, ensures the interdependence between postural control and movement function (Rothwell, 2009; Rothwell, 2012). These neuroanatomical and functional foundations explain the high probability of bilateral postural control impairment in subjects with stroke in subcortical areas and movement failure in the contralesional side (also named affected side) predominantly related to corticospinal system injury. In fact, the role of the reticular system over both sides of the body as to postural tone recruitment and modulation (Schepens et al., 2004) justifies the analyses of postural control function in both sides of the body in all motor tasks, and in all populations with or without pathology.

Although this line of reasoning is supported by neuroscientific knowledge, the research involving stroke subjects has given little attention to the comprehension of the behaviour of the ipsilesional side, usually referred to as the non-affected side (Hall et al., 2011; Lamontagne et al., 2002; Lamontagne et al., 2000; Milot et al., 2006; Peterson et al., 2010). Although some authors have already reported neuromotor dysfunctions in the ipsilesional limbs when compared to healthy controls (Hall et al., 2011; Lamontagne et al., 2002; Lamontagne et al., 2000; Milot et al., 2006), they explained the dysfunction as a compensatory strategy rather than as a consequence of the lesion (Higginson et al., 2006; Lamontagne et al., 2002; Lamontagne et al., 2000).

In relation to this issue, it is important to present the state-of-the-art that sustains the hypothesis that stroke subjects with lesion at the middle cerebral artery territory at a subcortical level show an atypical behaviour in the ipsilesional side associated with the lesion itself and to discuss the possible implications.

\section{2- Postural control dysfunction in the ipsilesional side}

To properly study the atypical behaviour associated with postural control dysfunction in the ipsilesional side it is important to select functional tasks that demand strong postural control. The sit-to-stand-to-sit and walking are good examples of this type of task (de Souza et al., 2011; Dehail et al., 2007; Galli et al., 2008; Hase et al., 2004) 
since they involve the coordination of joints along the kinematic chain to keep the centre of mass within the safe limits of the body's base of support (Freitas et al., 2009; Jacobs, 1997; Kiemel et al., 2008; Morasso et al., 1999; Nicholas et al., 1998; van der Kooij et al., 1999). Additionally, the lower limbs must be coordinated to provide support and stability (Sousa et al., 2013b), being recognised by the central nervous system as one functional unit. The study of tasks involving this functional unit enables identifying any atypical behaviour, since it depends on the role of the reticulospinal system in interlimb regulation (Schepens et al., 2004). Moreover, the study of these tasks must focus the subphases with higher postural control demand, i.e. the initial phase of sit-to-stand and standto-sit (Silva et al., 2012b; Silva et al., 2012c), middle stance (Silva et al., 2012d; Sousa et al., 2012a), double support (Silva et al., 2015; Sousa et al., 2013a; Sousa et al., 2013b) and gait initiation (Sousa et al., 2015a, 2015b).

The above-mentioned sub-phases are highly demanding from a postural control perspective as they require the modulation of ankle plantar flexors to adjust their tension/length relationship, without losing the antigravity postural control. Several authors have highlighted the importance of the information provided by type II (Maupas et al., 2004) and Ib fibre groups of ankle plantar flexors on postural control during locomotion (Faist et al., 2006; Knikou, 2008). In cases of central nervous system lesion, like stroke, the plantar flexor muscles are more prone to activation failure than the proximal muscles (i.e. quadriceps) (Klein et al., 2010). Specifically, the behaviour of the soleus as a postural muscle may reveal postural control dysfunction more evidently, since uniarticular muscles are thought to be more affected by central influences than by peripheral influences (Kautz et al., 2005). Based on the above, the soleus muscle could be expected to reflect more accurately the postural control dysfunction as a result of a possible lesion of the cortical-reticular system. Changes in the activation timing of the soleus and tibialis anterior muscles during sit-to-stand and stand-to-sit in post-stroke subjects support this notion (Silva et al., 2012b).

Similarly to what was observed during the first phase of sit-to-stand and stand-tosit, stereotyped activity patterns have been demonstrated during the first phase of gait initiation (Brunt et al., 1991; Brunt et al., 1999; Crenna et al., 1991; Elble et al., 1994; Fiolkowski et al., 2002; Shapiro et al., 1981). The inhibition of the tonically active soleus followed by the activation of the tibialis anterior early in gait initiation (Crenna et al., 1991; Elble et al., 1994; Jian et al., 1993) enable the backward displacement of the centre of pressure (Brunt et al., 1991; Crenna et al., 1991), contributing to postural stability 
(Massion, 1992; Mcllroy et al., 1999), as well as the optimum generation of momentum at the end of the first step to reach the steady-state gait (Lepers et al., 1995). Recent studies have demonstrated that subcortical post-stroke subjects present failure in modulating the soleus timing in both contralesional and ipsilesional limbs (Sousa et al., 2015a), which is associated with a decreased backward displacement of the centre of pressure (Sousa et al., 2015a, 2015b). This bilateral impairment reduces stability and performance in gait initiation. Considering that muscle activation's timing on postural adjustments depends on the corticoreticular connection, these findings suggest that this atypical behaviour is related to the lesion. The evidence demonstrating that the atypical behaviour of the ipsilesional plantar flexors changes according to their role during gait double support strengthens this association (Silva et al., 2015). Walking is the task where, in a rhythmic way, muscle roles change automatically. During double support, the trailing limb's soleus muscle provides body support (McGowan et al., 2008) while the gastrocnemius medialis is associated with forward progression (Anderson et al., 2003; Hall et al., 2011; Neptune et al., 2001). The leading limb's ankle dorsiflexors attenuate the initial contact, being important in weight acceptance (Winter, 1983). In fact, the hypothesis that the neuronal injury is the cause for the ipsilesional limb's atypical behaviour instead of a compensatory mechanism is supported both by the fact that the performance of ipsilesional plantar flexors, in stroke subjects, changes according to the limb's position (Silva et al., 2015) and by the fact that, during step-to-step transition, the contralesional limb is influenced by the ipsilesional limb and not the opposite (Sousa et al., 2013a). This also reinforces the evidence that the muscles associated with the ventral-medial systems' activity may present a more pronounced atypical behaviour while assuming an agonist role.

The previously exposed opens the discussion as to the connection between some efferent systems and specific muscles. The close relation between ventral-medial systems and the activity of postural muscles like the soleus (Horn, 2004) may justify the selection of this muscle to assess the output of ventral-medial efferent systems over the lower limb. In fact, the large contribution from group Ib fibres to the amplitude modulation of the soleus muscle activity during weight-bearing activities (Mazzaro et al., 2006) and the strong role of reticulospinal pathways on group II fibres (Davies et al., 1994; MarchandPauvert et al., 2005) highlight the connection between this muscle and the reticular system. The assessment of muscle activity considering that movement's capacity also depends on postural control ability demands an integration of both limbs' evaluation in the rehabilitation of post-stroke subjects. 


\section{3- Implications for practice and concluding remarks}

For a long time, the ipsilesional side has been considered the non-affected side and therefore the reference to identify the dysfunction of the contralesional side. This reference has been used both in the clinical practice and in research. This approach may have negative consequences in the decision-making process, as it: 1) limits the identification of a possible ipsilesional impairment related to postural control; 2) limits the gains in the rehabilitation process, since movement failure of the contralesional side is also related to ipsilesional postural control dysfunction (gait initiation is an example of this pre-requisite); 3) compromises the inter-limb coordination necessary for most functional activities, particularly during walking, as strategies are focused on the contralesional limb's behaviour only.

There is evidence pointing that post-stroke subjects with lesion in the middle cerebral territory present impairments also in the ipsilesional limbs and, because of this, both limbs should be considered along the rehabilitation program, as both interfere with movement performance and postural control regulation.

\section{4- References}

Anderson, F. C., \& Pandy, M. G. 2003. Individual muscle contributions to support in normal walking. Gait Posture 17(2): 159-169.

Brunt, D., Lafferty, M. J., Mckeon, A., Goode, B., Mulhausen, C., \& Polk, P. 1991. Invariant Characteristics of Gait Initiation. American Journal of Physical Medicine \& Rehabilitation 70(4): 206-212.

Brunt, D., Liu, S.-M., Trimble, M., Bauer, J., \& Short, M. 1999. Principles underlying the organization of movement initiation from quiet stance. Gait \& Posture 10(2): 121-128.

Capaday, C., Lavoie, B. A., Barbeau, H., Schneider, C., \& Bonnard, M. 1999. Studies on the corticospinal control of human walking. I. Responses to focal transcranial magnetic stimulation of the motor cortex. Journal of neurophysiology 81(1): 129-139.

Carr, J. H., Shepherd, R. B., Nordholm, L., \& Lynne, D. 1985. Investigation of a New Motor Assessment Scale for Stroke Patients. Physical Therapy 65(2): 175-180.

Crafton, K. R., Mark, A. N., \& Cramer, S. C. 2003. Improved understanding of cortical injury by incorporating measures of functional anatomy. Brain 126(7): 1650-1659.

Crenna, P., \& Frigo, C. 1991. A motor programme for the initiation of forward-oriented movements in humans. Journal of Physiology 437: 635-653.

Davies, H. E., \& Edgley, S. A. 1994. Inputs to group II-activated midlumbar interneurones from descending motor pathways in the cat. The Journal of Physiology 479(Pt 3): 463-473.

de Souza, L. A., Curtarelli Mde, B., Mukherjee, M., \& Dionisio, V. C. 2011. The effect of the partially restricted sit-to-stand task on biomechanical variables in subjects with and without Parkinson's disease. Journal of electromyography and kinesiology : official journal of the International Society of Electrophysiological Kinesiology 21(5): 719-726.

Dehail, P., Bestaven, E., Muller, F., Mallet, A., Robert, B., Bourdel-Marchasson, I., \& Petit, J. 2007. Kinematic and electromyographic analysis of rising from a chair during a "Sit-to- 
Walk" task in elderly subjects: role of strength. Clinical biomechanics (Bristol, Avon) 22(10): 1096-1103.

Di Giulio, I., Maganaris, C., Baltzopoulos, V., \& Loram, I. 2009. The proprioceptive and agonist roles of gastrocnemius, soleus and tibialis anterior muscles in maintaining human upright posture. Journal of Physiology 587(10): 2399-2416.

Elble, R. J., Moody, C., Leffler, K., \& Sinha, R. 1994. The initiation of normal walking. Movement Disorders 9(2): 139-146.

Faist, M., Hoefer, C., Hodapp, M., Dietz, V., Berger, W., \& Duysens, J. 2006. In humans Ib facilitation depends on locomotion while suppression of $\mathrm{Ib}$ inhibition requires loading. Brain research 1076(1): 87-92.

Fiolkowski, P., Brunt, D., Bishop, M., \& Woo, R. 2002. Does postural instability affect the initiation of human gait? Neuroscience Letters 323(3): 167-170.

Freitas, P. B. d., Freitas, S. M. S. F., Duarte, M., Latash, M. L., \& Zatsiorsky, V. M. 2009. Effects of joint immobilization on standing balance. Human Movement Science 28(4): 515528.

Galli, M., Cimolin, V., Crivellini, M., \& Campanini, I. 2008. Quantitative analysis of sit to stand movement: experimental set-up definition and application to healthy and hemiplegic adults. Gait Posture 28(1): 80-85.

Gowland, C., Stratford, P., Ward, M., Moreland, J., Torresin, W., Van Hullenaar, S., ... Plews, N. 1993. Measuring physical impairment and disability with the Chedoke-McMaster Stroke Assessment. Stroke 24(1): 58-63.

Hall, A. L., Peterson, C. L., Kautz, S. A., \& Neptune, R. R. 2011. Relationships between muscle contributions to walking subtasks and functional walking status in persons with poststroke hemiparesis. Clinical biomechanics (Bristol, Avon) 26(5): 509-515.

Hase, K., Sako, M., Ushiba, J., \& Chino, N. 2004. Motor strategies for initiating downwardoriented movements during standing in adults. Experimental brain research. Experimentelle Hirnforschung. Experimentation cerebrale 158(1): 18-27.

Higginson, J. S., Zajac, F. E., Neptune, R. R., Kautz, S. A., \& Delp, S. L. 2006. Muscle contributions to support during gait in an individual with post-stroke hemiparesis. J Biomech 39(10): 1769-1777.

Horn, E. R. 2004. "Critical periods" in vestibular development or adaptation of gravity sensory systems to altered gravitational conditions? Archives italiennes de biologie 142(3): 155-174.

Jacobs, R. 1997. Control model of human stance using fuzzy logic. Biol Cybern 77(1): 63-70.

Jian, Y., Winter, D. A., Ishac, M. G., \& Gilchrist, L. 1993. Trajectory of the body COG and COP during initiation and termination of gait. Gait \& Posture 1(1): 9-22.

Kautz, S. A., \& Patten, C. 2005. Interlimb influences on paretic leg function in post-stroke hemiparesis. Journal of neurophysiology 93(5): 2460-2473.

Kiemel, T., Elahi, A. J., \& Jeka, J. J. 2008. Identification of the plant for upright stance in humans: multiple movement patterns from a single neural strategy. Journal of neurophysiology 100(6): 3394-3406.

Klein, C. S., Brooks, D., Richardson, D., Mcllroy, W. E., \& Bayley, M. T. 2010. Voluntary activation failure contributes more to plantar flexor weakness than antagonist coactivation and muscle atrophy in chronic stroke survivors. Journal of applied physiology (Bethesda, Md. : 1985) 109(5): 1337-1346.

Knikou, M. 2008. The H-reflex as a probe: pathways and pitfalls. Journal of neuroscience methods 171(1): 1-12.

Lamontagne, A., Malouin, F., Richards, C. L., \& Dumas, F. 2002. Mechanisms of disturbed motor control in ankle weakness during gait after stroke. Gait \& Posture 15(3): 244255. 
Lamontagne, A., Richards, C. L., \& Malouin, F. 2000. Coactivation during gait as an adaptive behavior after stroke. Journal of electromyography and kinesiology : official journal of the International Society of Electrophysiological Kinesiology 10(6): 407-415.

Lepers, R., \& Brenière, Y. 1995. The role of anticipatory postural adjustments and gravity in gait initiation. Experimental Brain Research 107(1): 118-124.

Marchand-Pauvert, V., Nicolas, G., Marque, P., Iglesias, C., \& Pierrot-Deseilligny, E. 2005. Increase in group II excitation from ankle muscles to thigh motoneurones during human standing. The Journal of Physiology 566(1): 257-271.

Massion, J. 1992. Movement, posture and equilibrium: interaction and coordination. Progress in Neurobiology 38: 35-56.

Maupas, E., Marque, P., Roques, C. F., \& Simonetta-Moreau, M. 2004. Modulation of the transmission in group II heteronymous pathways by tizanidine in spastic hemiplegic patients. Journal of neurology, neurosurgery, and psychiatry 75(1): 130-135.

Mazzaro, N., Grey, M., do Nascimento, O., \& Sinkjær, T. 2006. Afferent-mediated modulation of the soleus muscle activity during the stance phase of human walking. Experimental Brain Research 173(4): 713-723.

McGowan, C. P., Neptune, R. R., \& Kram, R. 2008. Independent effects of weight and mass on plantar flexor activity during walking: implications for their contributions to body support and forward propulsion. Journal of Applied Physiology 105(2): 486-494.

Mcllroy, W. E., \& Maki, B. E. 1999. The control of lateral stability during rapid stepping reactions evoked by antero-posterior perturbation: does anticipatory control play a role? Gait \& Posture 9(3): 190-198.

Milot, M. H., Nadeau, S., Gravel, D., \& Requiao, L. F. 2006. Bilateral level of effort of the plantar flexors, hip flexors, and extensors during gait in hemiparetic and healthy individuals. Stroke 37(8): 2070-2075.

Mohr, J., Lazar, R., \& Marshall, R. (2004). Middle cerebral artery disease. In J. Mohr, R. Lazar, \& R. Marshall (Eds.), Stroke: Pathophysiology, Diagnosis and Management (pp. 123-166). New York: Elsiever.

Morasso, P. G., \& Schieppati, M. 1999. Can muscle stiffness alone stabilize upright standing? Journal of neurophysiology 82(3): 1622-1626.

Neptune, R., Kautz, A., \& Zajac, E. 2001. Contributions of the individual ankle flexors to support, forward progression and swing initiation during normal walking. Journal of Biomechanics 34(11): 1387-1398.

Nicholas, S., Doxey-Gasway, D., \& Paloski, W. 1998. A link-segment model of upright human posture for analysis of head-trunk coordination. Journal of Vestibular Research: Equilibrium \& Orientation 8(3): 187-200.

Parvataneni, K., Olney, S. J., \& Brouwer, B. 2007. Changes in muscle group work associated with changes in gait speed of persons with stroke. Clinical biomechanics (Bristol, Avon) 22(7): 813-820.

Peterson, C. L., Hall, A. L., Kautz, S. A., \& Neptune, R. R. 2010. Pre-swing deficits in forward propulsion, swing initiation and power generation by individual muscles during hemiparetic walking. Journal of Biomechanics 43(12): 2348-2355.

Rothwell, J. 2009. Meet the brain neurophysiology. International review of neurobiology 86: 51-65.

Rothwell, J. C. 2012. Overview of neurophysiology of movement control. Clinical neurology and neurosurgery 114(5): 432-435.

Schepens, B., \& Drew, T. 2004. Independent and convergent signals from the pontomedullary reticular formation contribute to the control of posture and movement during reaching in the cat. Journal of neurophysiology 92(4): 2217-2238.

Schiemanck, S. K., Kwakkel, G., Post, M. W. M., Kappelle, L. J., \& Prevo, A. J. H. 2006. Predicting long-term independency in activities of daily living after middle cerebral artery stroke. Stroke 37(4): 1050-1054. 
Shapiro, D. C., Zernicke, R. F., Gregor, R. J., \& Diestel, J. D. 1981. Evidence for Generalized Motor Programs Using Gait Pattern Analysis. Journal of Motor Behavior 13(1): 33-47.

Silva, A., Sousa, A., Pinheiro, A., Tavares, J., Santos, R., \& Sousa, F. 2012a. Soleus activity in post-stroke subjects: movement sequence from standing to sitting. Somatossensory and Motor Research (in press).

Silva, A., Sousa, A. S. P., Pinheiro, R., Ferraz, J., Tavares, J. M. R. S., Santos, R., \& Sousa, F. 2012b. Activation timing of soleus and tibialis anterior muscles during sit-to-stand and stand-to-sit in post-stroke vs healthy subjects. Somatossensory and Motor Research 30(1): 48-85.

Silva, A., Sousa, A. S. P., Pinheiro, R., Tavares, J. M. R. S., Santos, R., \& Sousa, F. 2012c. Soleus activity in post-stroke subjects: movement sequence from standing to sitting. Somatossensory and Motor Research 29(3): 71-76.

Silva, A., Sousa, A. S. P., Silva, C., Tavares, J. M. R. S., Santos, R., \& Sousa, F. 2015. Ankle antagonist coactivation in the double-support phase of walking: Stroke vs. healthy subjects. Somatosensory \& Motor Research: 1-5.

Silva, A., Sousa, A. S. P., Tavares, J., Tinoco, A., Santos, R., \& Sousa, F. 2012d. Ankle dynamic in stroke patients. Agonist vs antagonist muscle relations. Somatosensory and Motor Research 29(4): 111-116.

Sousa, A. S. P., Silva, A., \& Santos, R. 2015a. Ankle anticipatory postural adjustments during gait initiation in healthy and post-stroke subjects. Clinical Biomechanics.

Sousa, A. S. P., Silva, A., \& Santos, R. 2015b. Reliability of Two Methods for Identifying the Postural Phase of Gait Initiation in Healthy and Post-stroke Subjects. Journal of Applied Biomechanics (in press).

Sousa, A. S. P., Silva, A., Santos, R., Sousa, F., \& Tavares, J. M. R. S. 2013a. Interlimb Coordination During the Stance Phase of Gait in Subjects With Stroke. Archives of Physical Medicine and Rehabilitation 94(12): 2515-2522.

Sousa, A. S. P., Silva, A., \& Tavares, J. M. R. S. 2013b. Interlimb relation during the double support phase of gait: an electromyographic, mechanical and energy based analysis. Proceedings of the Institution of Mechanical Engineers, Part $\mathrm{H}$ : Journal of Engineering in Medicine 227(3).

Sousa, A. S. P., \& Tavares, J. M. R. S. 2012a. Effect of gait speed on muscle activity patterns and magnitude during stance. Motor Control 16: 480-492.

Sousa, A. S. P., \& Tavares, J. M. R. S. (2012b). Surface electromyographic amplitude normalization methods: a review. In H. Takada (Ed.), Electromyography: New Developments, Procedures and Applications (pp. 85-101). New York: Nova Science Publishers, Inc.

van der Kooij, H., Jacobs, R., Koopman, B., \& Grootenboer, H. 1999. A multisensory integration model of human stance control. Biol Cybern 80(5): 299-308.

Wang, C.-H., Hsieh, C.-L., Dai, M.-H., Chen, C.-H., \& Lai, Y.-F. 2002. Inter-rater reliability and validity of the stroke rehabilitation assessment of movement (STREAM) instrument. Journal of Rehabilitation Medicine (Taylor \& Francis Ltd) 34(1): 20-24.

Winter, A. 1983. Energy generation and absorption at the ankle and knee during fast, natural and slow cadences. Clinical Orthopaedics 175: 147-157. 